\title{
E-Mentoring to Address Youth Health: A Systematic Review
}

\author{
Michelle R. Kaufman ${ }^{1}(1) \cdot$ Deb Levine $^{2} \cdot$ Albert Casella $^{3} \cdot$ David L. DuBois $^{4}$
}

Received: 13 April 2021 / Accepted: 31 August 2021 / Published online: 18 September 2021

(c) The Author(s), under exclusive licence to Springer Nature Switzerland AG 2021

\begin{abstract}
Electronic mentoring (e-mentoring), the integration of digital technology in mentoring relationships, has recently grown in popularity; however, the effectiveness of e-mentoring in addressing youth health has not been synthesized to date. The current study synthesizes the literature on e-mentoring to affect the health and well-being of youth (10-24 years) through a systematic review and evidence quality assessment. A total of 833 records were identified, of which 14 met eligibility criteria (published in English since 1995, targeted youth health and/or youth with health issues, and communication was entirely digital or combined with in-person interaction). The results showed that the majority of health-focused e-mentoring studies were conducted with young people with existing health conditions rather than on the use of e-mentoring to promote overall health and wellness. The included programs focused largely on bringing mentoring to youth subpopulations that may be challenged by in-person models. Quality assessments of the included studies showed that the strength of the evidence is mediocre. The findings suggest that e-mentoring has the potential to reach youth with unique health concerns and to promote independent management of health conditions as youth transition to adulthood; however, more rigorous evaluation of e-mentoring programs with larger sample sizes is needed.
\end{abstract}

Keywords Youth $\cdot$ Mentoring $\cdot$ Digital communication $\cdot$ Health $\cdot \mathrm{e}$-health $\cdot$ mHealth

\section{Introduction}

In recent years, electronic mentoring (e-mentoring) has grown in popularity due to the proliferation of digital communication and the constant use of technology by adolescents (Rideout \& Robb, 2019; Shpigelman, 2013), particularly as a result of the COVID-19 pandemic (Kaufman et al., 2021). While technology is now being incorporated into a variety of mentoring programs targeting multiple youth subgroups and outcomes of interest, evidence regarding the effectiveness of using technology to facilitate mentoring is still nascent. Digital technology has been used with some

Michelle R. Kaufman

MichelleKaufman@jhu.edu

1 Department of Health, Behavior \& Society, Johns Hopkins Bloomberg School of Public Health, 624 N. Broadway, Room 257, Baltimore, MD 21204, USA

2 DKF Productions, Oakland, CA, USA

3 Johns Hopkins University Center for Communication Programs, Baltimore, MD, USA

4 School of Public Health and Institute for Health Research and Policy, University of Illinois Chicago, Chicago, IL, USA success in the context of health behavior interventions, such as health-focused apps and telehealth, and may inform the incorporation of technology into health-focused youth mentoring. However, the state of the literature on the combining of mentoring and technology as it impacts youth health has not been synthesized to date. Through a systematic review, this study synthesizes the literature on e-mentoring to improve health outcomes among youth.

Youth mentoring is defined as a process in which a nonparental adult or older peer, acting in a non-professional capacity, builds and maintains a supportive relationship with a young person (DuBois et al., 2011). Mentors provide guidance, support, and encouragement to cultivate healthy development (DuBois et al., 2011; Stoff, 2016). Mentoring has been widely adopted as an intervention strategy to promote the academic success, social-emotional growth, and career readiness of youth and to prevent harmful behaviors that lead to poor outcomes (e.g., delinquency, truancy, substance use) as young people enter adulthood (USAID, 2016). Unlike mental health treatment and other types of health care, mentoring is provided by an individual without advanced professional training as a health care provider (e.g., licensed therapist). Consequently, with respect to mental health concerns, 
for example, mentors are not tasked with providing formal psychological or psychiatric interventions. Compared to formal mental health treatment and other health care, there are also typically fewer constraints on mentor-mentee interactions in terms of their frequency, location, modality (e.g., informal text or email exchanges), and the types of activities and discussions that may be involved. These differences may be conducive to developing deeper personal relationships than are typical of formal care and can provide a greater range of types of opportunities and resources for the mentees.

E-mentoring models vary depending on the needs of a program and/or the youth served. The most common models include: (1) exclusively digital communication between the mentor and mentee, (2) primarily digital communication with occasional in-person meetings, and (3) a majority of the mentoring occurring in person with digital communication supplementing the relationship (Shpigelman, 2013). E-mentoring programs may foster a unique space for the development of mentor/mentee relationships, emotional and instrumental support for youth, and youth-adult connectedness (Ensher et al., 2003; Shpigelman, 2013; Ware \& Ramos, 2013). Digital technology may also encourage deeper discussion of sensitive topics, such as sexual and reproductive health and mental health, thereby overcoming the shame and stigma many people find with face-to-face communication about such issues (Levine, 2011).

Previous research has defined a preliminary understanding of the potential impact of e-mentoring on youth outcomes such as academic success, school attendance, and improved peer relationships (Shpigelman, 2013). A 2017 review concluded there is mixed evidence for improving youth outcomes in a variety of domains (e.g., self-esteem, career readiness, academic achievement, etc.) and found that sustainable e-mentoring programs have benefited from clear guidelines, structure, and organizational tools (Kaufman, 2017). There is also published evidence suggesting that general online support mechanisms (other than e-mentoring) can improve young people's health indicators, such as depressive thoughts and the effects of bullying (Cole et al., 2017).

\section{Current Study}

Despite the increased use of digital communication among youth, including in mentoring relationships, the research on e-mentoring as it impacts youth health has not been synthesized to date. The objective of this systematic review was to examine the empirical literature on e-mentoring initiatives designed to improve youth health outcomes, as mentors are well positioned to guide youth on engaging in healthy behaviors that they can carry into late adolescence and young adulthood. E-mentoring could enhance the ability for mentoring relationships to address sensitive health topics or increase access to mentors for youth with particular health concerns. The current review sought to address what populations of youth (age range, gender, health status, etc.) are being targeted for healthrelated e-mentoring (Research Question 1) and to assess evidence for the efficacy of e-mentoring interventions for improving youth health outcomes (Research Question 2).

\section{Methods}

This review was conducted and reported in accordance with the guidance provided by the Preferred Reporting Items for Systematic Reviews and Meta-Analysis (PRISMA) statement (Moher et al., 2009). No registered protocol exists for this systematic review.

\section{Information Sources}

A systematic literature search was conducted to identify peer reviewed articles that mention e-mentoring for youth and thus were potentially eligible for inclusion in the systematic review. Given the interest in both adolescent and young adult health in the context of mentoring, studies of young people (aged 10-24 years), in line with the World Health Organization's definition of youth, were included. For this review, e-mentoring refers to a meaningful relationship between a young person and an adult or an older peer with shared life experience who is acting in a nonprofessional capacity. The mentoring could be conducted entirely or in part using digital communication, such as email, text, social media, messaging applications, video calls, or computer platforms used as tools to develop the relationship. This includes the use of technology to support and/or enhance in-person mentoring relationships (e.g., using email communication to stay in touch between in-person meetings to further grow the relationship). For the purposes of this review, e-mentoring does not include the use of web or mobile device-based resources intended for in-person use by a mentor and mentee together. For example, if a mentoring pair uses a website to practice skills while together in person, this was not included as e-mentoring, but if they use a website/mobile app to interact and keep in touch between in-person visits, that was included. In addition, studies of mentoring programs that consisted of only digital mentor training modules (training tools viewed only by mentors) were not included in this review. 


\section{Search}

A targeted search was conducted in December 2019 using the library databases PubMed, Scopus, PsycINFO, and Embase. Key search terms included children, youth, e-mentoring, online mentoring, electronic mentoring, digital mentoring, and variants of these terms (see Table 1). The reference lists of included studies were searched for additional publications not detected in the key word search. Research referenced in chapters and prior literature reviews pertinent to e-mentoring were also reviewed for potential relevance (Howarth et al., 2018; Lindsay et al., 2018).

\section{Study Selection}

Studies were included in the review if they met the following criteria: (1) published between 1995 and 2019 (1995 was chosen due to this being the year the Internet became mainstream in Silicon Valley); (2) written in English; (3) focused on a mentoring program that targeted youth health outcomes (i.e., measures of health behaviors and/or physical or mental well-being) and/or youth with health issues; and (4) communication and interaction between mentor(s) and mentee(s) in the program was entirely digital or combined with in-person interaction.
Studies were excluded if they: (1) mentioned the inclusion of an e-mentoring component but instead reported on a telemedicine tool for youth and/or their parents that did not involve the development of a meaningful mentoring relationship and/or was provided in the context of professional care (e.g., using technology for remote diagnosis and treatment of patients); (2) did not focus on youth as the potential beneficiaries of the mentoring; (3) reported formative research for intervention development; and (4) were commentaries, conference abstracts, unpublished dissertations, or gray literature and/or reports. Some mentoring programs include e-mentoring in their program design but do not have the resources to conduct evaluations or publish their findings in peer-reviewed journals. Thus, the published literature included in this review may be biased towards those programs that have sufficient support to conduct evaluations and publish findings.

Figure 1 presents a PRISMA diagram to illustrate the literature search, screening, and review process. Following the key word search, two study team members independently screened titles and abstracts in separate steps for inclusion based upon review criteria. Screeners placed an article in a "proceed" or "do not proceed" folder, which was compared and reviewed by the study team. In cases where there was disagreement, team members discussed the specific study in accordance with the inclusion criteria and determined

Table 1 Key terms used in database searches

\begin{tabular}{|c|c|}
\hline Subject area & Key words \\
\hline Youth & 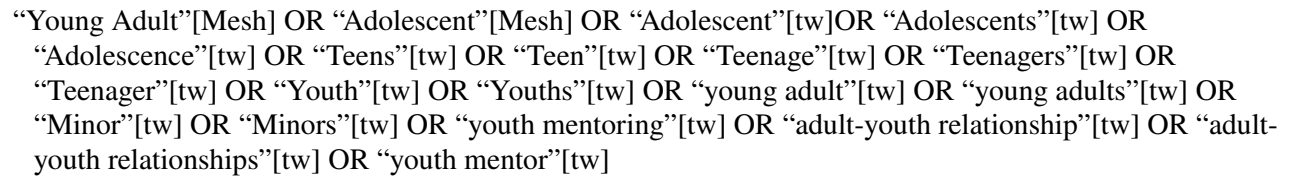 \\
\hline E-mentoring & 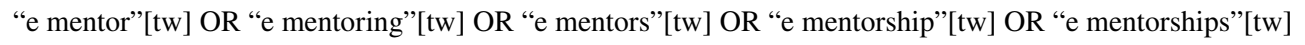 \\
\hline Online mentor & $\begin{array}{l}\text { "online mentor" }[\mathrm{tw}] \mathrm{OR} \text { "online mentoring" }[\mathrm{tw}] \mathrm{OR} \text { "online mentors" }[\mathrm{tw}] \text { OR "online mentorship" }[\mathrm{tw}] \mathrm{OR} \\
\text { "online mentorships" }[\mathrm{tw}] \text { or "mentor online" }[\mathrm{tw}]\end{array}$ \\
\hline Electronic mentor & 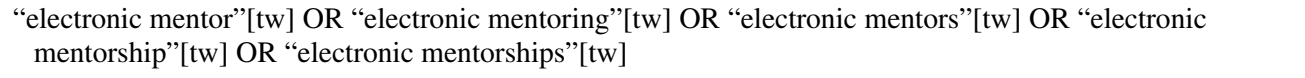 \\
\hline Digital mentor & $\begin{array}{l}\text { “digital mentor" }[\mathrm{tw}] \mathrm{OR} \text { “digital mentoring”[tw] OR “digital mentors"[tw] OR “digital mentorship”[tw] OR } \\
\text { "digital mentorships”[tw] }\end{array}$ \\
\hline Tele mentor or Telementor & $\begin{array}{l}\text { “tele mentor”[tw] OR “tele mentoring”[tw] OR “tele mentors”[tw] OR “tele mentorship”[tw] OR "tele } \\
\text { mentorships”[tw] } \\
\text { "telementor"[tw] OR “telementoring”[tw] OR “telementors"[tw] OR “telementorship”[tw] OR } \\
\text { "telementorships”[tw] }\end{array}$ \\
\hline Virtual mentor & $\begin{array}{l}\text { “virtual mentor" }[\mathrm{tw}] \mathrm{OR} \text { “virtual mentoring”[tw] OR "virtual mentors" }[\mathrm{tw}] \text { OR “virtual mentorship" }[\mathrm{tw}] \mathrm{OR} \\
\text { "virtual mentorships"[tw] }\end{array}$ \\
\hline Social media mentor & $\begin{array}{l}\text { "social media mentor" [tw] OR "social media mentoring” }[\mathrm{tw}] \text { OR "social media mentors"[tw] OR "social } \\
\text { media mentorship" }[\mathrm{tw}] \text { OR "social media mentorships"[tw] }\end{array}$ \\
\hline Other relevant key search terms & $\begin{array}{l}\text { "computer mediated" }[\mathrm{tw}] \\
\text { "e-development"[tw] } \\
\text { "digital media in mentoring" [tw] } \\
\text { "mentoring through technology"[tw] }\end{array}$ \\
\hline
\end{tabular}

Note: Articles needed to include one term from the "Youth" subject area and at least one other key word 


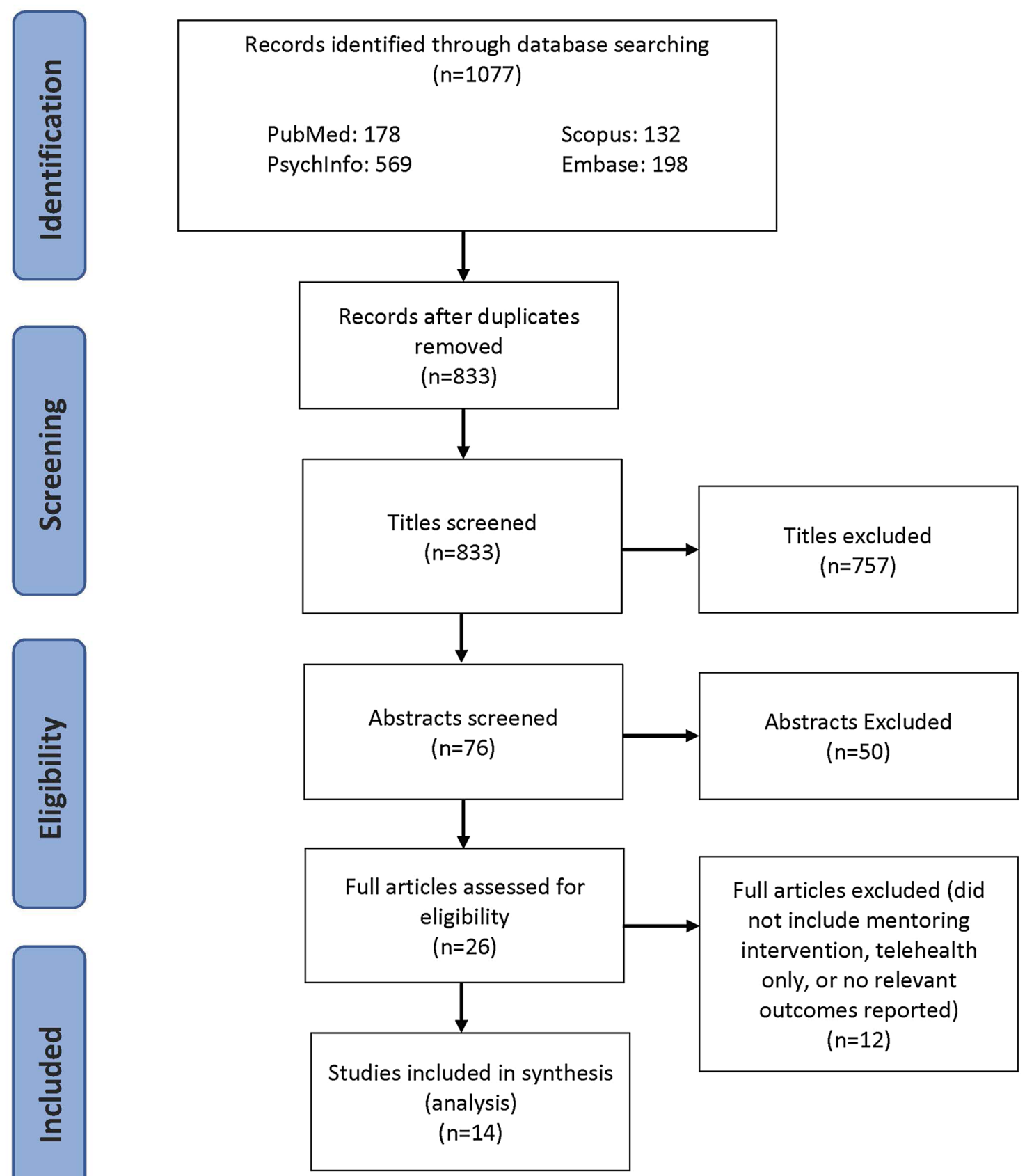

Fig. 1 PRISMA diagram

whether the article in question would proceed along the review cascade. Following the preliminary title screen, article abstracts were read to determine whether the article had the potential to fit all inclusion criteria. These articles then proceeded to full review.

Data abstraction for each study included the following: year of publication, characteristics of mentees and mentors, sample size, e-mentoring intervention, outcomes assessed, and outcome statistics. Included articles were reviewed in detail using the National Institute for Health Care Excellence (NICE) quality appraisal checklists for qualitative and quantitative studies (NICE, 2012) to determine the strength of the evidence presented. Each included article was coded and scored by one of the authors, with 20 percent of the articles double coded. 


\section{Results}

\section{Overview of Studies Included}

Of the 833 records identified after removing duplicates, 76 potentially relevant full text articles were reviewed for eligibility, of which 14 studies, representing analyses of data from 9 independent samples, met the eligibility criteria and were included in the final review (see Table 2). Several studies reported the details of interventions for youth with health challenges but did not report on the effect of mentoring on their health outcomes per se (Grant \& Dieker, 2011; Perry et al., 2010; Rhodes et al., 2006; Shpigelman \& Gill, 2013). Some papers also reported protocols or formative work, but any follow up papers with intervention results were not located (Heida et al., 2018; Lindsay et al., 2017; Rice \& Barman-Adhikari, 2014). Studies also included very small sample sizes, often because the studies were in the pilot phase (Grant \& Dieker, 2011; Perry et al., 2010; Shpigelman \& Gill, 2013).

\section{Study Characteristics and Results}

None of the studies included in the review reported the impact of e-mentoring on specific health behaviors or outcomes (such as nutrition, fitness, substance use prevention). Rather, studies reported on factors that may precede such health behaviors, such as social-emotional outcomes, self-efficacy of the mentees to manage their health condition, perceived social acceptance, or an overall sense of emotional well-being because of the mentoring. Studies that have been published to date have focused on reporting e-mentoring interventions that targeted a subpopulation of youth with a given health issue and the impact of said mentoring on amelioration of the particular health challenge (such as pain management or reduction in depressive symptoms). The quality of the quantitative studies was mediocre, with just two that were coded as fulfilling most items required for the quality assessment (Gregg et al., 2017; Stinson et al., 2016), five fulfilling some of the criteria, and one fulfilling few or no items in the checklist. The quality of the qualitative studies was much higher, with six fulfilling all or most of the criteria in the checklist and two fulfilling some of the criteria (see Table 2). While studies often mentioned the ages of the mentees and mentors, and sometimes the gender or other demographic characteristics, they tended to not analyze results by mentee developmental stage or gender. Findings are described relating to these factors for studies in which they were included.

The presentation of the included studies is divided by three health conditions-chronic conditions, transplant recipients, and disabilities. Most of the studies measured the effect of e-mentoring for youth with physical and/or mental disabilities.

\section{Chronic Health Conditions}

Three studies (all utilizing the same multiple methods data set) focused on juvenile idiopathic arthritis (JIA) and reported the results of one particular e-mentoring program, iPeer2Peer. These studies reported health outcomes for youth in terms of their ability to manage JIA (Kohut et al., 2017, 2018; Stinson et al., 2016). While this program was evaluated using a waitlist randomized controlled trial (Stinson et al., 2016) and using multiple data collection methods (Kohut et al., 2017, 2018), the sample size was very small, even for a pilot program $(n=15$ mentoring pairs). A vast majority of the mentors (90.9\%) and the mentees (93\%) were female. The studies reported that mentees demonstrated improvements in their perceived ability to manage JIA (Stinson et al., 2016) and may have provided unexpected support for mentors' own illness self-management, as mentors were slightly older peers who also had JIA (Kohut et al., 2017). Peer mentors provided and received both informational support (knowledge, facts, advice on actions) and emotional support (caring, concern, empathy, sympathy) from both mentees and fellow mentors (Kohut et al., 2017). Mentoring pairs tended to spend time discussing the impact of their illness and self-management, but they also focused on nonillness related issues relevant to youth (e.g., post-secondary goals, hobbies, social environments) (Kohut et al., 2018).

Challenge Your Arthritis is an online self-management tool with peer mentoring for youth ages 16-25 with rheumatic disease. A feasibility study was conducted to evaluate the usefulness, ease of use, and user acceptance of the online tool (Ammerlaan et al., 2014). Mentee participants found the online tool helpful and showed high achievement of selfassessed goals they set for themselves for self-management of their disease (e.g., handling tiredness, pain, and feeling blue; getting support from others; anger management). No outcomes other than user experience and goal achievement were measured.

One study looked at an online peer support intervention for young teens with asthma and/or severe allergies (Letourneau et al., 2012). The peer mentors, all of whom themselves had rheumatic disease, provided chat support weekly for three months. Results showed few significant differences from pre- to post-intervention, with the exception of a significant reduction in loneliness; however, the sample size was very small $(n=10)$. Girls attended fewer chat sessions than did boys. Qualitative interviews with the youth revealed evidence of possible positive effects of the program, including increased confidence and ability to talk with others about their condition as a result of the intervention. 


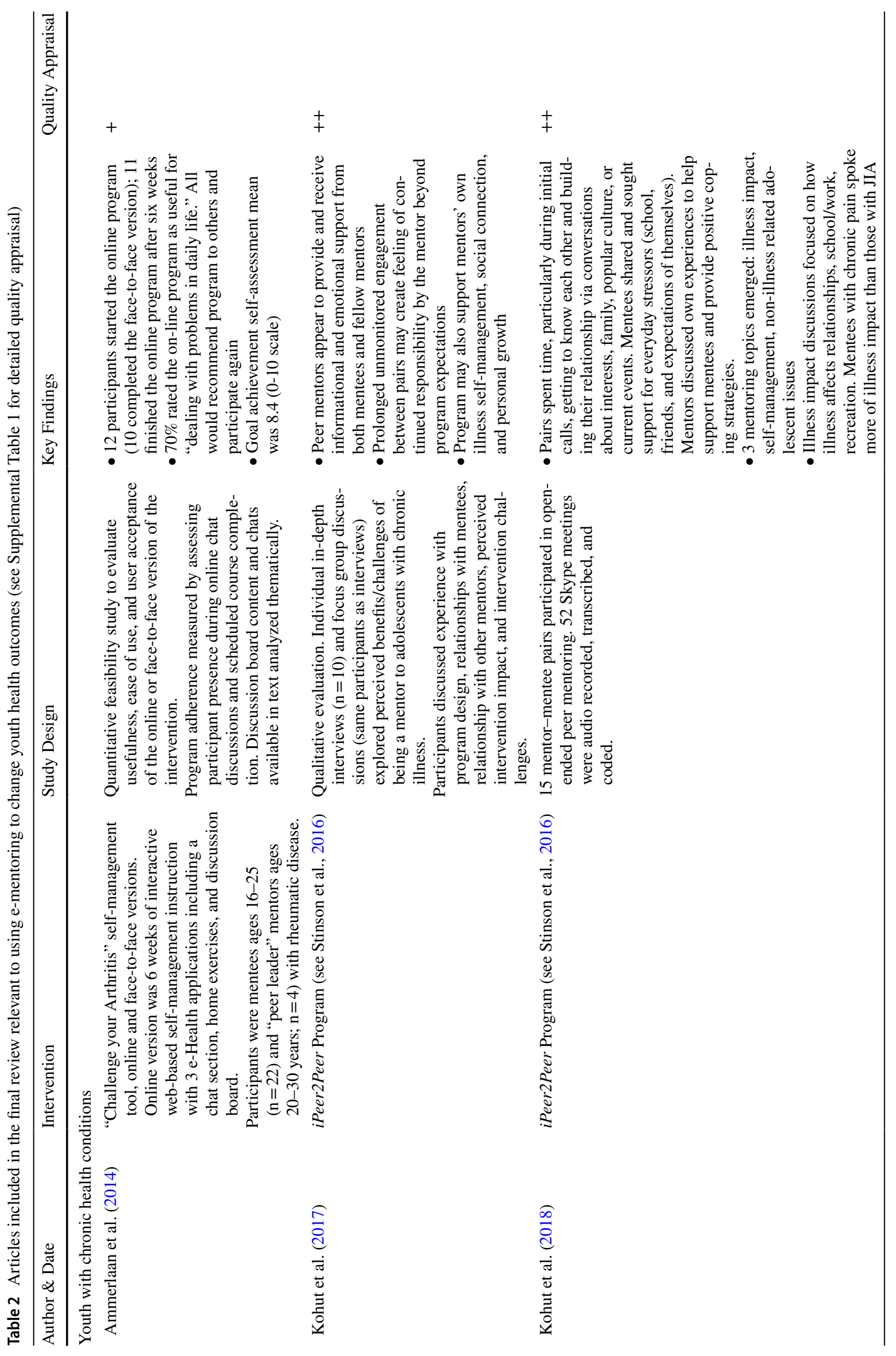




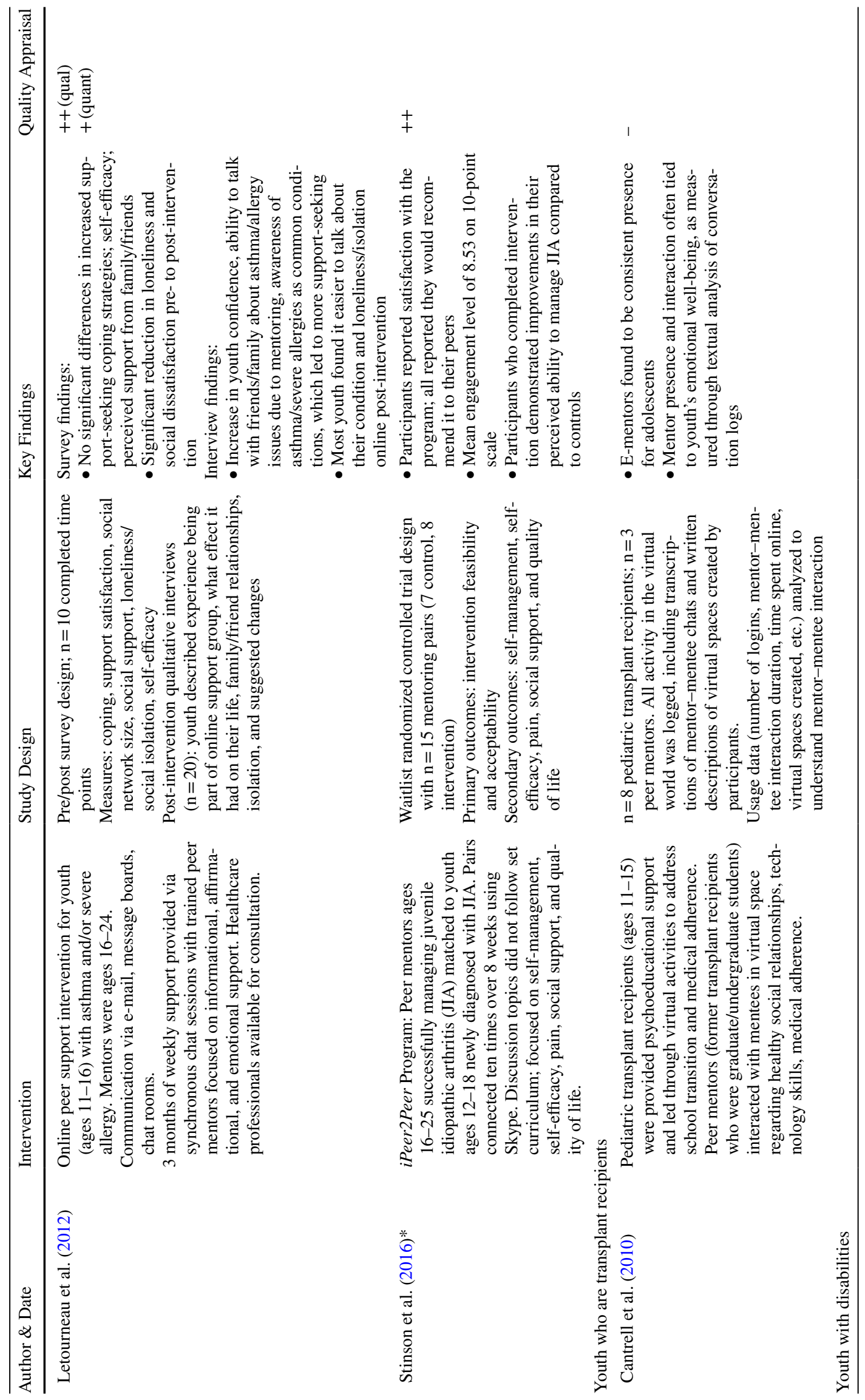




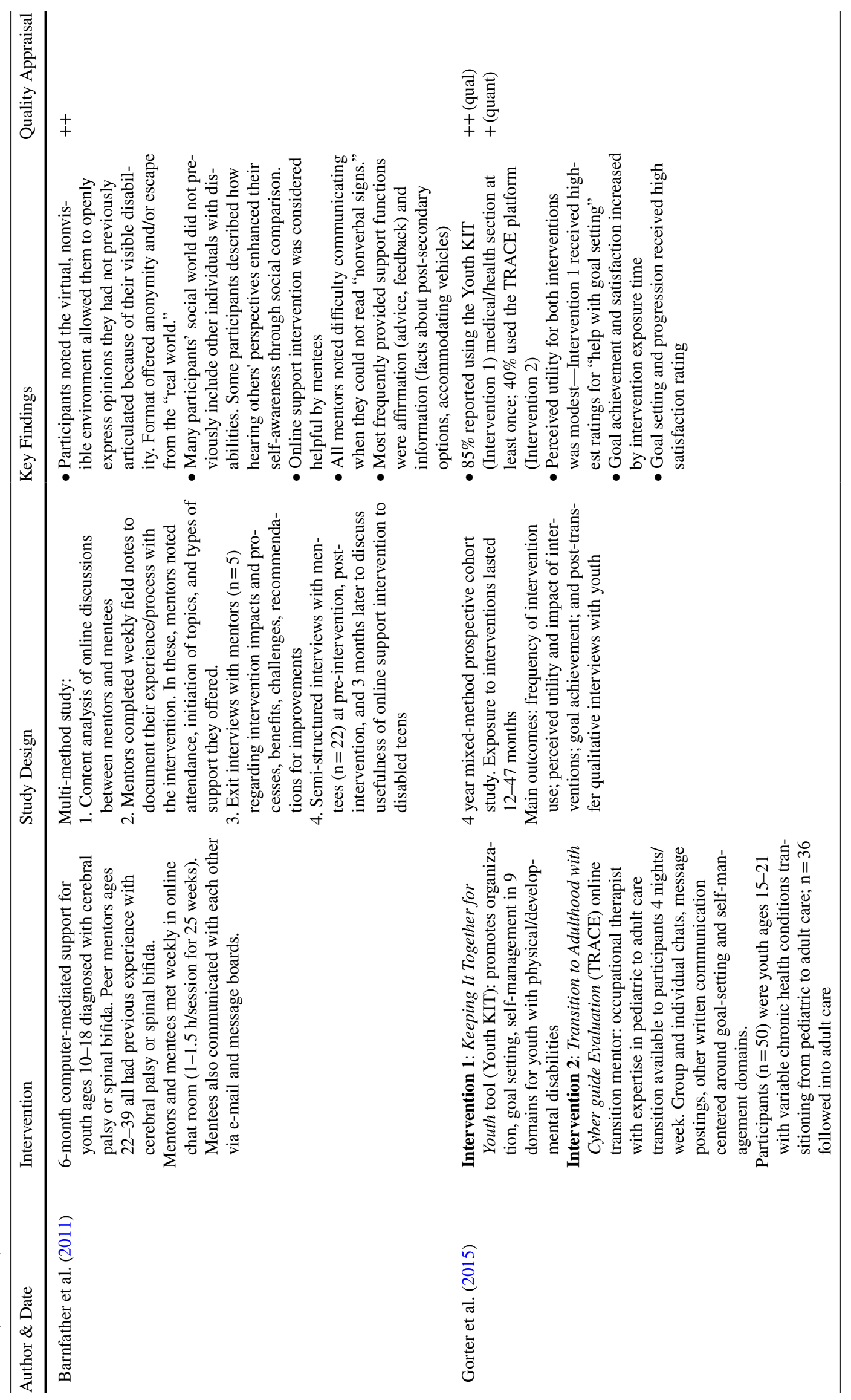




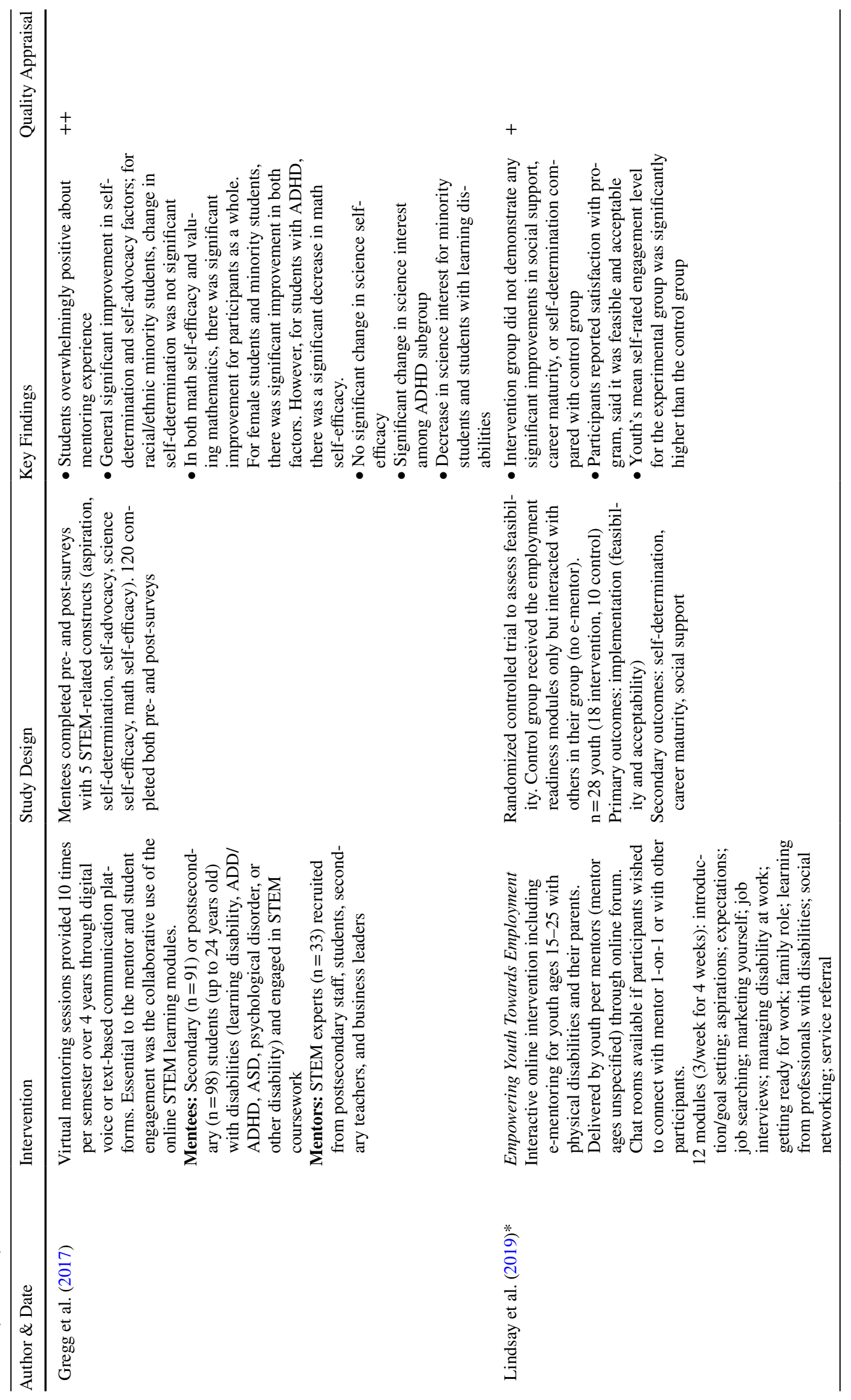




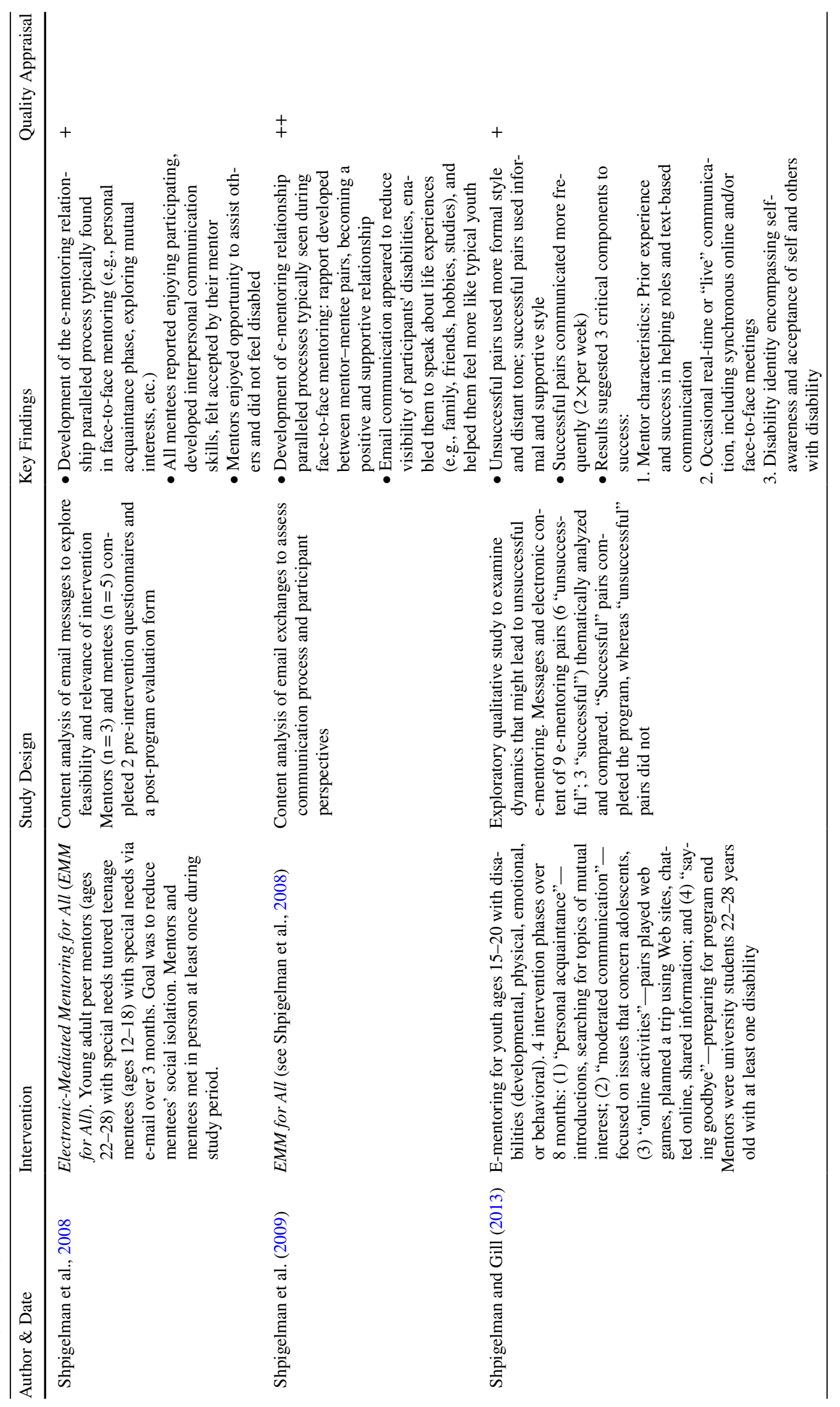




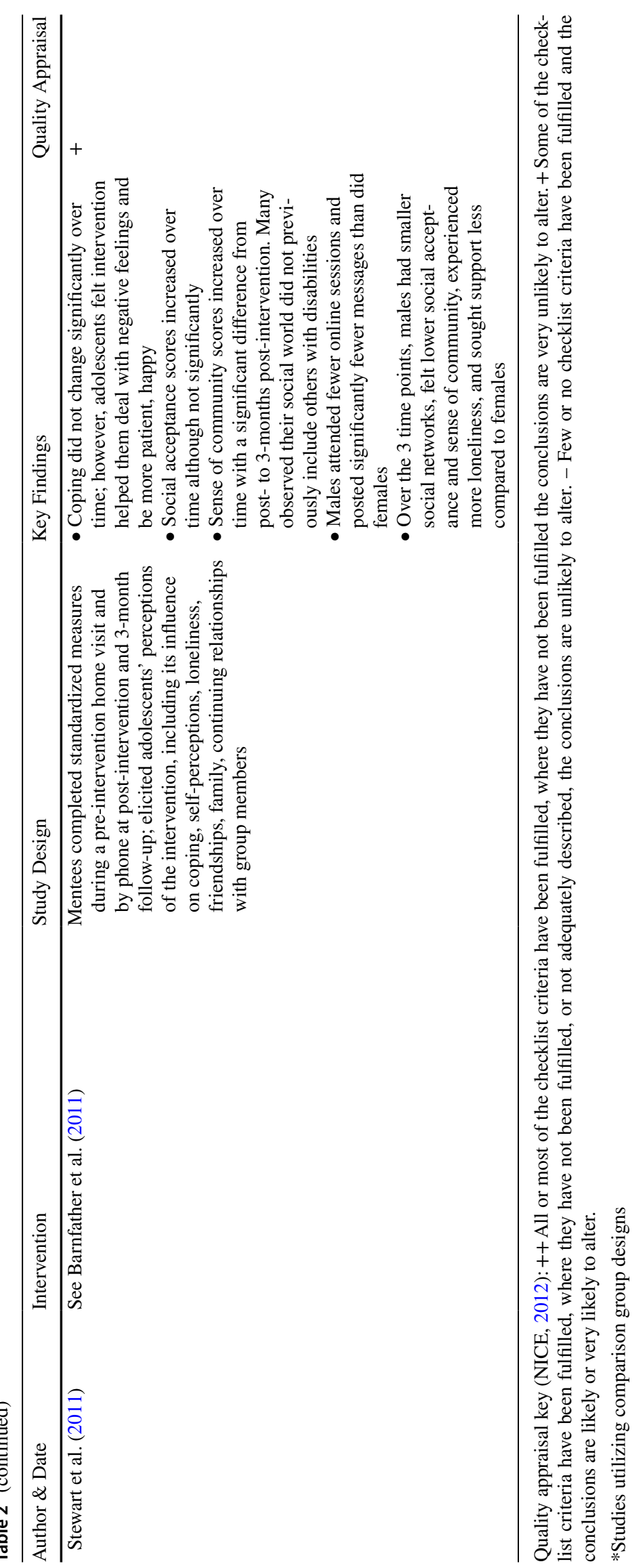




\section{Transplant Recipients}

A study of peer e-mentoring for pediatric transplant patients (Cantrell et al., 2010) looked at technology usage data (logins, interaction duration, virtual spaces created) to understand the mentor/mentee interaction and explore potential effects of the mentoring on mentee well-being through a textual analysis of the conversational logs. When e-mentors were a consistent presence for the youth, this was reported to be tied to an apparent improvement in the mentee's emotional well-being.

\section{Disabilities}

A majority of the included studies focused on youth with various types of disabilities, including physical, mental, and learning. Although these studies did not report changes in health outcomes related to the disability, they did focus on providing access and resources to these youth. For instance, the Keeping It Together for Youth toolkit and the Transition to Adulthood with Cyber Guide Evaluation (TRACE) interventions (both reported in one paper) were designed to help youth with physical disabilities improve their self-management of daily life and transition to adulthood (Gorter et al., 2015). The study used a longitudinal mixed-method prospective cohort design, with 50 youth participants enrolled and 36 retained into the adult assessments. Engagement with the interventions was rather low; however, those who used them reported high satisfaction, and goal achievement and satisfaction increased in association with the amount of time spent using each intervention. Engagement of females was found to be higher than males for these interventions.

The Empowering Youth Towards Employment program is an online intervention with e-mentoring for youth with physical disabilities (Lindsay et al., 2019). The program was tested for feasibility in a randomized controlled trial with 28 youth, but no health outcomes were measured. No significant effects were found for the intervention group compared to a control group with the exception that youth engagement in the program was higher in the intervention group (which included e-mentoring) compared to the control group (no e-mentoring).

Shpigelman and colleagues have studied e-mentoring for youth with various disabilities for many years. One early study looked at an email-facilitated mentoring program called Electronic-Mediated Mentoring for All, in which teen mentees with special needs were paired with young adult peer mentors who also had special needs (Shpigelman et al., 2008). In a content analysis of the email messages, the e-mentoring relationship seemed to develop in a similar way to in-person mentoring relationships (personal acquaintance phase, exploring mutual interests, etc.). Data showed that mentees enjoyed the program, felt accepted by their mentors, and that mentors appreciated the opportunity to assist others. A second study also analyzing email exchanges from this program reported evidence that email communication may have helped to reduce the visibility of participant disabilities and helped mentees to feel like more "typical" youth (Shpigelman et al., 2009).

Another study from this group was a qualitative outcomes study of e-mentoring for youth ages 15-20 with disabilities (Shpigelman \& Gill, 2013). The e-mentors were slightly older university students with at least one disability. The authors identified three key components that may have contributed to an e-mentoring relationship being successful: mentor characteristics (prior experience in helping roles and text-based communication); incorporation of real-time communication via chats or face-to-face video meetings; and a mentor whose identity is one of acceptance of their own and others' disabilities. Outcomes beyond relationship success were not reported.

One study looked at computer-mediated peer support for youth with cerebral palsy and spinal bifida in which teenage mentees and young adult mentors with the same condition met weekly in online chat rooms (Barnfather et al., 2011). A multi-method analysis showed that participants felt free to openly express themselves in the online space, they developed enhanced self-awareness through knowing someone else with their condition, and they received emotional and instrumental support from their mentors. In this study, girls posted significantly more messages than did boys. A second study assessing the outcomes of the program from preintervention to immediate post-intervention and a 3-month follow-up found that the teenagers' self-reported coping ability did not change significantly over time (Stewart et al., 2011). Measures of social acceptance and sense of community did increase significantly. A comparison of outcomes by gender revealed that males attended fewer online sessions than did females, females posted more messages than did males, and males reported having smaller social networks, lower social acceptance and sense of community, and more loneliness. Male mentees also sought support less than did female mentees.

One study looked at a STEM (science, technology, engineering, and math)-focused virtual mentoring program for students with disabilities (learning, attention, psychological disorders, etc.) (Gregg et al., 2017). In a pre-/post-evaluation design, results showed improvements in self-reported self-determination and self-advocacy; however, racial/ethnic minority students did not exhibit the same change in self-determination as did majority students. There was also a decrease in interest in science for minority students and students with learning disabilities, suggesting the virtual platform was not helpful and perhaps even detrimental for some students' STEM interests. 


\section{Discussion}

With the rise in digital communication technology, e-mentoring has emerged as a feasible intervention for youth. Studies published over the past decade have focused on various models of e-mentoring, including using it to address health and well-being. This review was conducted to synthesize and examine the methodological quality of the literature on e-mentoring initiatives designed to improve youth health outcomes.

The first research question, which sought to describe the types of youth targeted by e-mentoring, is still largely unanswered. The types of health status are clearer; youth with chronic health conditions, disabilities, or those who received an organ transplant have been included in e-mentoring studies focused on health outcomes. However, the studies are too disparate across multiple health conditions to draw any definitive conclusions. Notwithstanding this limitation, it is clear that the interventions included in this review largely focused on bringing mentoring to youth subpopulations that may be challenged by in-person mentoring models-those with unique health needs and/or those with physical limitations that may make it difficult for them to engage in traditional, friend-based, in-person mentoring (Guse et al., 2012; Kaufman, 2017).

The gender of participants as it related to outcomes was largely unreported in these studies; Barnfather et al. (2011), Gorter et al. (2015), and Stewart et al. (2011) were exceptions. For all other studies, if participants' gender was reported, the sample sizes were generally too small to merit meaningful analyses by gender, or in the case of the iPeer2Peer program, a vast majority of the participants were female. Other studies pointed to a lack of analysis by mentee gender in their limitations (e.g., Kohut et al., 2017, 2018; Shpigelman \& Gill, 2013).

The age range of youth targeted also varied considerably between studies, often with wide age ranges within single studies (e.g., 12 to 18 years), and the researchers did not specify findings related to early, middle, and/or late adolescence. It seems that older youth on the cusp of adulthood, and therefore beginning the transition to managing a health condition more independently, were the primary targets of the interventions in these studies. This emphasis makes sense, as mentoring could help with the transition to independent living and health condition management. However, future research will need to focus more deliberately on the developmental stages of youth to help clarify the appropriateness of e-mentoring for multiple stages of adolescence.

The second research question to be addressed by this review regarding the efficacy of e-mentoring interventions focused on health also remains largely unanswered.
The qualitative evidence reviewed was generally of high quality, but the quantitative studies are largely underpowered and do not include comparison groups, limiting their impact. Furthermore, while the research included in this review shows some promise for digital mentoring to effectively reach youth with health and disability concerns, no research to date has looked at how digital mentoring can improve health outcomes for young people beyond the selected aspect of psychosocial well-being (e.g., perceived ability to manage chronic conditions, feeling like a "typical" teenager).

Digital mentoring has been shown to bring the opportunities that face-to-face mentoring typically provides to youth who may not be easily reached by in-person models (e.g., rural youth, youth with few mentors in their community who share career goals, etc.) (Kaufman, 2017; Lindsay et al., 2018). What remains unknown is whether digital mentoring can serve as a form of primary or secondary prevention of various health issues for youth as they move from adolescence into adulthood or as a way to address and manage diagnosed health conditions. While some of the studies included in this review show promising evidence of the latter, there is not sufficient evidence to make claims about the positive impact of digital mentoring on youth health. The types of digital mentoring programs that are developmentally appropriate for specific age ranges in young people are not known. The studies addressed varying health issues (several chronic conditions, transplant recipients, disabilities) and rarely looked at the impact of the program against a comparison group in which youth did not receive the mentoring. The disperse nature of the literature at this point does not allow for any definitive conclusions to be made; however, feedback from study participants and initial findings showing positive trends provide promise for the field of digital mentoring to positively impact youth health.

Given these positive trends, digital mentoring could be utilized to have conversations between adults and youth about sensitive health issues that can be more difficult to discuss when face-to-face. Digital mentoring models could be used by mentors in primary prevention efforts to talk about stigmatized health behaviors such as substance use, sexual behavior, and mental health concerns without the mentee feeling judged by their mentor during face-to-face interactions (Guse et al., 2012). This type of programming would necessitate mentors who are sufficiently skilled in empathy and digital communication and well-educated on the health subject matter. Depending on the focus of the program, mentors may also need to have on-call access to licensed practitioners if issues arise beyond those that can be handled by a paraprofessional such as a mentor.

Digital mentoring could also be used to help mentees manage health behaviors such as nutrition, exercise, and stress reduction, much like online health coaching programs 
operate for adults (Howarth et al., 2018). It could be used to supplement clinical care, whereby a mentor could help a young person with information seeking about their diagnosis, guide the youth on how to navigate the logistics of managing a health condition (e.g., medical appointments, medication adherence, accommodations as needed), and provide emotional support such as reassurance and encouragement during periods of frustration and affirmation of feelings. Such mentoring support has shown to be effective in improving health outcomes when conducted in in-person settings but with limited reach and adoption (Dennis, 2003; Kohut et al., 2018; Sansom-Daly et al., 2012). E-mentoring as a supplement to clinical care could fill the gaps in this reach and may be especially important for youth who are transitioning to adulthood and learning to independently manage a health condition.

With traditional mentoring programs often targeting lowincome youth and those in low-resource settings, the perceived lack of access to technology may have contributed to the limited number of digital mentoring programs for such youth. The "digital divide" has certainly made technologydriven programs inaccessible to some youth of lower socioeconomic status or in low-income areas (Watkins, 2012; Watkins et al., 2013); however, the presence of free Wi-Fi hotspots and less expensive digital devices and data plans has decreased this divide (Clark, 2017). But disparities in technology access still exist for some youth in terms of how easily they can access mobile devices and reliable internet connections, as illustrated during the COVID-19 pandemic and need for remote learning (Lee, 2020; Patrick, 2020; Ramsetty \& Adams, 2020). Future digital mentoring programs should take this factor into account. None of the studies included in this review addressed the issue of technology access, as all mentor and mentee participants were either provided a device and sufficient mobile data or were required to have it to meet study eligibility.

Another area for future research involves identity and self-image issues that can be addressed via e-mentoring. If youth with health concerns or disabilities feel like more "typical" youth as a result of guidance from a mentor (Barnfather et al., 2011; Letourneau et al., 2012; Shpigelman \& Gill, 2013), particularly one with a shared experience, this may help facilitate longer term outcomes, such as academic achievement, disability or illness management, or coping with health issues. E-mentoring could potentially impact positive identity development, serving as a mediator for achieving desired program outcomes. There may also be benefits to mentors in these digital mentoring programs (Kohut et al., 2017; Shpigelman et al., 2008), as they are provided with an opportunity to share their own journey with health challenges with a young person just beginning that path (if the mentor has a shared experience). While mentor benefits were not a focus of this review, few studies examined any impact on the mentors working with youth, despite the mentors often sharing health experiences similar to the mentees.

There are some limitations to this systematic review. The focus was on e-mentoring interventions that targeted health and wellness outcomes for youth; however, the state of the research showed a focus on e-mentoring for young people with existing health challenges. The next phase in research on digital mentoring should include examination of the use of e-mentoring platforms for use with larger, more diverse youth populations as a form of disease prevention and health promotion. This review was also limited in that it is focused on published peer-reviewed papers. Gray literature, doctoral dissertations, and other unpublished articles could add more substance to the body of knowledge in this nascent field of study, especially given that so many programs tend to have small numbers of participants, thus making it difficult to find statistically significant effects in evaluations and potentially leading to publication bias.

The strengths of this review are that it summarizes a nascent but important field-the use of digital technology to enhance youth mentoring. This review was systematic and utilized a quality assessment checklist to determine the strength of this evidence to date. This review's focus on health issues revealed additional potential benefits of e-mentoring beyond its ability for mentoring to be accessed by hard-to-reach youth. Such technology-driven or -enhanced mentoring programs allow young people who suffer from a potentially stigmatizing condition or characteristic to receive mentorship even if they are physically unable to engage in more traditional community-based mentoring programs. E-mentoring also allows youth with health conditions to be matched with other individuals with a similar experience regardless of the mentor's geographic proximity, which may allow the youth to normalize their feelings and challenges and to receive practical guidance from someone who understands their experience first-hand. Although preliminary, existing findings suggest that such mentorship may allow youth with health concerns to learn more productive coping strategies and the life skills necessary for a successful transition to adulthood and independent management of a health condition.

\section{Conclusion}

E-mentoring has grown in popularity as a way to combine technology and mentoring to connect more youth with mentors that fit their specific needs. Despite its popularity, knowledge about the effectiveness of e-mentoring for young people is limited, particularly in the context of health-focused mentoring. This study summarized and assessed the existing literature on e-mentoring to affect 
youth health through a systematic review of peer-reviewed literature and an assessment of the literature quality. The review showed that e-mentoring in the context of health is focused largely on youth with specific health conditions, with assessed outcomes focused primarily on youth selfefficacy and the social-emotional aspects of dealing with a health condition. The currently available literature does not shed meaningful light on the impact of e-mentoring on the health of mentees by developmental stage or gender, with many studies too small in sample size to conduct meaningful analyses by youth subgroups. The quality of the literature is variable, with higher quality found in qualitative studies compared to quantitative-focused studies, for which quality was mediocre. Despite the early stage of the literature on e-mentoring to improve youth health, findings of the available studies indicate promise for e-mentoring's ability to reach subpopulations of youth that may be physically unable to meet with mentors in person or that have unique health conditions where a mentor may be difficult to find. Results also are consistent with a potential for e-mentoring for youth health to help youth learn the skills necessary to manage a health condition or disability as they transition to independence in adulthood. Given the ubiquitous use of digital technology to facilitate communication, specifically health communication, it is incumbent upon mentoring programs and health researchers to continue to study the potential effectiveness of e-mentoring to improve the health and well-being of young people.

Supplementary Information The online version contains supplementary material available at https://doi.org/10.1007/s40894-021-00172-3.

Acknowledgements We are thankful to Fasika Alem for leading the literature search for an earlier report that directly informed the current review, and to Mike Garringer who contributed the practice implications of that report and helped us to think about the implications of e-mentoring specific to youth health outcomes. We are also grateful to Kim Dam for the initial literature searches and screening for this review, to Alicia Bazell for assisting with references and formatting, and to Carl Latkin and Nick Ialongo for their mentorship on our studies focused on e-mentoring.

Authors' Contributions MK conceptualized the review, led the search and screening process and quality assessment, and wrote the manuscript; DL contributed to the quality assessment, the interpretation of review findings and thinking about next steps for e-mentoring research for the discussion, and supported the writing of the manuscript; AC contributed to the search and screening process and wrote sections of the manuscript; and DD provided expertise on mentoring practice and contributed to writing the manuscript. All authors have read and approved the final manuscript.

Funding Research reported in this publication was supported by the National Institute on Drug Abuse of the National Institutes of Health under Award Number K01DA042138. The content is solely the responsibility of the authors and does not necessarily represent the official views of the National Institutes of Health.

\section{Declarations}

Conflict of interest The authors report no conflicts of interest.

\section{References}

Ammerlaan, J., van Os-Medendorp, H., Scholtus, L., de Vos, A., Zwier, M., Bijlsma, H., \& Kruize, A. A. (2014). Feasibility of an online and a face-to-face version of a self-management program for young adults with a rheumatic disease: Experiences of young adults and peer leaders. Pediatric Rheumatology Online Journal, 12, 10. https://doi.org/10.1186/1546-0096-12-10

Barnfather, A., Stewart, M., Magill-Evans, J., Ray, L., \& Letourneau, N. (2011). Computer-mediated support for adolescents with cerebral palsy or spina bifida. Computers Informatics Nursing, 29(1), 24-33. https://doi.org/10.1097/ncn.0b013e3181f9db63

Cantrell, K., Fischer, A., Bouzaher, A., \& Bers, M. (2010). The role of e-mentorship in a virtual world for youth transplant recipients. Journal of Pediatric Oncology Nursing, 27(6), 344-355. https:// doi.org/10.1177/1043454210372617

Clark, K. (2017). Practical applications of technology as a key to reducing the digital divide among African American youth. Journal of Children in Media, 11(2), 252-255. https://doi.org/10.1080/17482 798.2017.1306369

Cole, D., Zelkowitz, R., Roeder, K., \& Spinelli, T. (2017). Online social support for young people: Does it recapitulate in-person social support; can it help? Computers in Human Behavior, 68, 456-464. https://doi.org/10.1016/j.chb.2016.11.058

Dennis, C. L. (2003). Peer support within a health care context: A concept analysis. International Journal of Nursing Studies, 40(3), 321-332. https://doi.org/10.1016/S0020-7489(02)00092-5

DuBois, D. L., Rhodes, J. E., Silberthorn, N., \& Valentine, J. C. (2011). How effective are mentoring programs for youth? A systematic assessment of the evidence. Psychological Science in the Public Interest, 12(2), 57-91. https://doi.org/10.1177/1529100611 414806

Ensher, E. A., Heun, C., \& Blanchard, A. (2003). Online mentoring and computer-mediated communication: New directions in research. Journal of Vocational Behavior, 63(2), 264-288. https://doi.org/ 10.1016/s0001-8791(03)00044-7

Gorter, J. W., Stewart, D., Cohen, E., \& TRACE Study Group. (2015). Are two youth-focused interventions sufficient to empower youth with chronic health conditions in their transition to adult healthcare: A mixed-methods longitudinal prospective cohort study. British Medical Journal Open, 5, e007553. https://doi.org/10. 1136/bmjopen-2014-007553

Grant, D., \& Dieker, L. (2011). Listening to Black male student voices using web-based mentoring. Remedial and Special Education, 32(4), 322-333. https://doi.org/10.1177/0741932510362203

Gregg, N., Galyardt, A., Wolfe, G., Moon, N., \& Todd, R. (2017). Virtual mentoring and persistence in STEM for students with disabilities. Career Development and Transition for Exceptional Individuals, 40(4), 205-214. https://doi.org/10.1177/2165143416 651717

Guse, K., Levine, D., Martins, S., Lira, A., Gaarde, J., Westmorland, W., \& Gilliam, M. (2012). Interventions using new digital media to improve adolescent sexual health: A systematic review. Journal of Adolescent Health, 51(6), 535-543. https://doi.org/10.1016/j. jadohealth.2012.03.014

Heida, A., Dijkstra, A., Kobold, A. M., Rossen, J. W., Kindermann, A., Kokke, F., de Meij, T., Norbruis, O., Weersma, R. K., Wessels, M., Hummel, T., Escher, J., van Wering, H., Hendriks, D., Mearin, L., Groen, H., Verkade, H. J., \& van Rheenen, P. F. (2018). Efficacy of 
home telemonitoring versus conventional follow-up: A randomized controlled trial among teenagers with inflammatory bowel disease. Journal of Crohns and Colitis, 12(4), 432-441. https://doi.org/10. 1093/ecco-jcc/jjx169

Howarth, A., Quesada, J., Silva, J., Judycki, S., \& Mills, P. R. (2018). The impact of digital health interventions on health-related outcomes in the workplace: A systematic review. Digital Health, 4, 1-18. https:// doi.org/10.1177/2055207618770861

Kaufman, M. (2017). E-mentoring: National Mentoring Resource Center model review. Resource document. National Mentoring Resource Center. https://nationalmentoringresourcecenter.org/wp-content/ uploads/2021/01/E-Mentoring_Model_Review.pdf. Accessed 9 Sept 2021

Kaufman, M. R., Wright, K., Simon, J., Edwards, G., Thrul, J., \& DuBois, D. (2021). Mentoring in the time of COVID-19: An analysis of online focus groups with mentors to youth. American Journal of Community Psychology. https://doi.org/10.1002/ajcp.12543 epub ahead of print.

Kohut, S. A., Stinson, J., Forgeron, P., Luca, S., \& Harris, L. (2017). Been there, done that: The experience of acting as a young adult mentor to adolescents living with chronic illness. Journal of Pediatric Psychology, 42(9), 962-969. https://doi.org/10.1093/jpepsy/jsx062

Kohut, S. A., Stinson, J., Forgeron, P., van Wyk, M., Harris, L., \& Luca, S. (2018). A qualitative content analysis of peer mentoring video calls in adolescents with chronic illness. Journal of Health Psychology, 23(6), 788-799. https://doi.org/10.1177/1359105316669877

Lee, N. T. (2020). What the coronavirus reveals about the digital divide between schools and communities. Brookings Institute. https:// www.brookings.edu/blog/techtank/2020/03/17/what-the-coronavirus-reveals-about-the-digital-divide-between-schools-and-commu nities/. Accessed 9 Sept 2021

Letourneau, N., Stewart, M., Masuda, J. R., Anderson, S., Cicutto, L., McGhan, S., \& Watt, S. (2012). Impact of online support for youth with asthma and allergies: Pilot study. Journal of Pediatric Nursing, 27(1), 65-73. https://doi.org/10.1016/j.pedn.2010.07.007

Levine, D. (2011). Using technology, new media, and mobile for sexual and reproductive health. Sexuality Research and Social Policy, 8, 18-26. https://doi.org/10.1007/s13178-011-0040-7

Lindsay, S., Cagliostro, E., Stinson, J., \& Leck, J. (2019). A 4-week electronic-mentoring employment intervention for youth with physical disabilities: Pilot randomized controlled trial. Journal of Medical Internet Research, 2(1), e12653. https://doi.org/10.2196/12653

Lindsay, S., Kolne, K., \& Cagliostro, E. (2018). Electronic mentoring programs and interventions for children and youth with disabilities: Systematic review. JMIR Pediatrics and Parenting, 1(2), e11679. https://doi.org/10.2196/11679

Lindsay, S., Stinson, J., Stergiou-Kita, M., \& Leck, J. (2017). Improving transition to employment for youth with physical disabilities: Protocol for a peer electronic mentoring intervention. JMIR Research Protocols, 6(11), e215. https://doi.org/10.2196/resprot.8034

Moher, D., Liberati, A., Tetzlaff, J., Altman, D. G., \& The PRISMA Group. (2009). Preferred reporting items for systematic reviews and meta-analyses: The PRISMA statement. Plos Medicine, 6, e1000097. https://doi.org/10.1371/journal.pmed.1000097

National Institute for Health and Care Excellence (NICE). (2012, September 26). Methods for the development of NICE public health guidance (3rd edition). https://www.nice.org.uk/process/pmg4/resou rces/methods-for-the-development-of-nice-public-health-guidancethird-edition-pdf-2007967445701

Patrick, A. (2020). How the Covid-19 pandemic shed light on the digital divide. Government Technology. https://www.govtech.com/network/ How-the-COVID-19-Pandemic-Shed-Light-on-the-Digital-Divide. html. Accessed 9 Sept 2021

Perry, E. E., Zheng, K., Grogan-Kaylor, A., Newman, M. W., \& Veinot, T. C. (2010). Assessing the effect of a technology-based peer-mentoring intervention on renal teams' perceived knowledge and comfort level working with young adults on dialysis. Journal of Nephrology Social Work, 33, 8-12.

Ramsetty, A., \& Adams, C. (2020). Impact of the digital divide in the age of COVID-19. Journal of the American Medical Informatics Association, 27(7), 1147-1148. https://doi.org/10.1093/jamia/ocaa078

Rhodes, J. E., Spencer, R., \& Saito, R. N. (2006). Online mentoring: The promise and challenges of an emerging approach to youth development. Journal of Primary Prevention, 27, 497-513. https://doi.org/ 10.1007/s10935-006-0051y

Rice, E., \& Barman-Adhikari, A. (2014). Internet and social media use as a resource among homeless youth. Journal of Computer-Mediated Communication, 19(2), 232-247. https://doi.org/10.1111/jcc4.12038

Rideout, V., \& Robb, M. B. (2019). The common sense census: Media use by tweens and teens. Common Sense Media.

Sansom-Daly, U. M., Peate, M., Wakefield, C. E., Bryant, R. A., \& Cohn, R. J. (2012). A systematic review of psychological interventions for adolescents and young adults living with chronic illness. Health Psychology, 31(3), 380-393.

Shpigelman, C. N. (2013). Electronic media and mentoring. In D. L. DuBois \& M. J. Karcher (Eds.), Handbook of youth mentoring (2nd ed., pp. 259-272). Sage.

Shpigelman, C., \& Gill, C. (2013). The characteristics of unsuccessful e-mentoring relationships for youth with disabilities. Qualitative Health Research, 23(4), 463-475. https://doi.org/10.1177/10497 32312469115

Shpigelman, C. N., Reiter, S., \& Weiss, P. T. (2008). E-mentoring for youth with special needs: Preliminary results. Cyberpsychology and Behavior, 11(2), 196-200. https://doi.org/10.1089/cpb.2007.0052

Shpigelman, C. N., Weiss, P. T., \& Reiter, S. (2009). E-mentoring for all. Computers in Human Behavior, 25(4), 919-928. https://doi.org/10. 1016/j.chb.2009.03.007

Stewart, M., Barnfather, A., Magill-Evans, J., Ray, L., \& Letourneau, N. (2011). Brief report: An online support intervention: Perceptions of adolescents with physical disabilities. Journal of Adolescence, 34(4), 795-800. https://doi.org/10.1016/j.adolescence.2010.04.007

Stinson, J., Kohut, S. A., Forgeron, P., Amaria, K., Bell, M., Kaufman, M., Luca, N., Luca, S., Harris, L., Victor, C., \& Spiegel, L. (2016). The ipeer2peer program: A pilot randomized controlled trial in adolescents with juvenile idiopathic arthritis. Pediatric Rheumatology Journal Online, 14, 48. https://doi.org/10.1186/s12969-016-0108-2

Stoff, D. (2016). Future HIV mentoring programs to enhance diversity. AIDS and Behavior, 20, 318-325. https://doi.org/10.1007/ s10461-016-1502-y

USAID. (2016). Youth power: Promoting positive youth development. U.S. Department of State.

Ware, P., \& Ramos, J. (2013). First-generation college students: Mentoring through social media. International Journal of Mentoring and Coaching in Educaation, 2(2), 149-162. https://doi.org/10.1108/ IJMCE-02-2013-0009

Watkins, S. C. (2012). Digital divide: Navigating the digital edge. International Journal of Learning and Media, 3(2), 1-12.

Watkins, S. C., Lombana-Bermudez, A., Cho, A., Vickery, J. R., Shaw, V., \& Weinzimmer, L. (2013). The digital edge: How Black and Latino youth navigate digital inequality. New York University Press.

Publisher's Note Springer Nature remains neutral with regard to jurisdictional claims in published maps and institutional affiliations. 